\section{Simplicity: the ultimate sophistication}

\author{
Philip Glasgow
}

Efficient movement underpins all great sporting performances. When performed by an expert, complex movements can appear effortless, almost simple; as Leonardo Da Vinci stated, "simplicity is the ultimate sophistication".

Dynamic control of movement is also central to safe sporting function and is dependent on the sophisticated integration of a range of factors including environment, nature of the task, feedforward input, afferent feedback as well as individual motor capabilities. The current issue of BJSM considers many of these features highlighting the complexity and multifactorial nature of running-related injuries as well as underlining the importance of return to sport decisions.

\section{BORN TO RUN OR LEARN TO RUN?}

The interaction of internal and external factors in sports injury has been well described, ${ }^{1}$ and is highlighted in the current issue. The role of footwear (or absence thereof), foot shape, dynamic proximal control as well as the specific effects of loading are all evaluated and remind us as clinicians that we need to consider the wider picture when recommending specific interventions.

For example, the practice of advising stability shoes for runners with pronated feet has been a staple for many years. While Theisen and colleagues (see page 370) did not observe any relationship between midsole hardness and running-related injury, they did report an increased rate of injury in novice runners and reduced incidence of injury in runners who engaged in sporting activities besides running. Engagement in other sporting activities may provide some protection in terms of tissue adaptation; it may also facilitate a motor system that is able to adopt optimal motor strategies during running. Running may, therefore, be

Correspondence to Dr Philip Glasgow, Department of Sports Medicine, Sports Institute Northern Ireland, University of Ulster, Jordanstown, Newtownabbey BT37 0QB, UK; philglasgow@sini.co.uk viewed as a skill that requires time to learn and that movement variability in terms of loading patterns and motor strategies may provide some level of protection.

Tam et al (see page 349) provide an assessment of barefoot running and its clinical application. The authors summarise some of the key elements of running mechanics that may be related to injury. They highlight that running barefoot may positively influence certain variables while simultaneously negatively influencing others. A key conclusion is that barefoot running should be viewed as a learned skill and as such the principles of motor learning and skill acquisition should be considered. An interesting approach would be to view shod running as a learned skill that should be taught in the same manner.

\section{RETURN TO SPORT: DO WE ALL KNOW BEST?}

Decisions regarding return to sport (RTS) are central to sports medicine practice, yet little is known about what criteria clinicians base judgements on. Given that so much research has been published on ACL reconstruction and rehabilitation, one might expect there to be a strong body of evidence guiding RTS decisions in this area. Perhaps disappointingly, Czuppon et al (see page 356) have identified only weak evidence for RTS criteria. The authors highlight that while we can identify variables associated with good functional outcome and patient satisfaction following ACL reconstruction, few studies have examined whether these variables are also associated with effective return to sport.

RTS decisions are inherently challenging and require a team approach. Shrier et al (see page 393) provide a fascinating insight into some of the decision-making processes that clinicians and sports-related professions use when determining fitness to compete. Interestingly, they observed that each profession viewed their own discipline as being best placed to make decisions regarding the athlete's ability to RTS. This highlights that in the broad church of sports medicine where integrated working is essential, a greater effort is required to facilitate understanding of the specific strengths of each discipline.

\section{EVALUATING THE COMPLEX-SOME SIMPLE PRINCIPLES}

Perhaps it is the complexity of RTS decisions that make them so difficult to evaluate; this is not a problem unique to sports medicine. Over the past five decades, physiotherapy research has increased significantly. However, Kamper et al (see page 346) provide a clear challenge highlighting that when sports physiotherapy trials are compared with other areas of physiotherapy research, they tend to have less rigorous methods. The authors provide practical advice for effective trial design and present us all with a challenge to simply evaluate what are perceived as complex and sophisticated problems.

\section{PHYSIOS IN SPORT UK}

Following the success of the biennial conference in Glasgow last October, Physios in Sport are planning two equally rewarding 1-day conferences in 2014. In March, Bristol will play host to Let's get Physical; we will move to Manchester in November where the theme is Don't get Hamstrung by Knee Problems. Both days will feature national and international experts and are sure to challenge, inform and entertain. Visit http://www.physiosinsport.org for more details.

\section{Competing interests None.}

Provenance and peer review Not commissioned; internally peer reviewed.

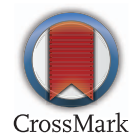

To cite Glasgow P. Br J Sports Med 2014;48:345. Accepted 18 December 2013

Br J Sports Med 2014;48:345.

doi:10.1136/bjsports-2013-093357

\section{REFERENCE}

1 Bahr R, Holme I. Risk factors for sports injuries-a methodological approach. Br J Sports Med 2003;37:384-92. 